\title{
REFLEXIONS AL VOLTANT D'UNA REFORMA QUE NO VA SER: LA REFORMA DEL CICLE SUPERIOR D'E.G.B.
}

A finals del curs 1984-85 el Departament d'Ensenyament de la Generalitat de Catalunya va proposar a les escoles de la ciutat de Valls la participació en el "Pla d'Experimentació de la Reforma del Cicle Superior d'EGB" que s'havia iniciat a començaments d'aquell mateix curs a 16 escoles d'arreu de Catalunya. La nostra escola, el C.P. Escola Enxaneta, va creure convenient acollir-se a aquesta convocatòria, i després de presentar la documentació sol.licitada, al setembre ens vam incorporar a aquest programa.

L'objectiu d'aquesta experimentació era posar en pràctica $i$ validar (si es donava el cas) un nou Disseny Curricular per als alumnes de Cicle Superior que substituís la programació de Segona Etapa de la Llei d'Educació de l'any 1970 i que donés continuïtat a la reforma dels Cicles Inicial i Mitjà que ja estaven en funcionament. Aquest Disseny Curricular s'havia d'estendre, posteriorment $i$ progressiva, a la resta d'escoles de Catalunya.

Paral.lelament, en alguns instituts de BUP i d'FP s'experimentava la Reforma del Primer Cicle d'Ensenyament Secundari (l'anomenat "tronc comú").

Aquest Pla d'Experimentació perd la seva funció al començar un nou enfocament de Reforma que es concreta al decretar l'ensenyament obligatori fins als 16 anys i a l'estructurar-se l'Educació Primària (612 anys) i l'Educació Secundària Obligatòria (12-16 anys).

\section{Què vam experimentar?}

El Departament d'Ensenyament proposà un nou Disseny Curricular (D.C) que incorporava en els seus criteris bàsics una referència explícita a les característiques psicopedagògiques dels alumnes a qui va destinat. Es parteix de la base que els alumnes d'aquesta edat presenten unes característiques específiques que no es poden deixar de banda i que marquen profundament la seva vida, tant a nivell escolar com a nivell general. Aquest fet de pensar en els alumnes abans que en les programacions concretes és ja de per si força positiu.

Es pretén que els aprenentatges que l'alumne faci siguin el màxim de significatius possible, és a dir, que les noves incorporacions que vagi fent represen- tin un pas més que li permetin establir connexions entre el que ja sap i el que aprèn. Aquest pas ha de ser prou gran perquè li permeti avançar, però no tan gran que li impedeixi el lligam entre l'estadi on l'alumne es troba i aquell a què hom desitja que arribi.

Contempiar aquesta premissa implica acceptar la diversitat d'alumnes a l'aula, ja que cada alumne es troba en el seu estadi i el pas que ha de fer no ha de ser igual per a tothom, i per tant la dificultat serà diferent per a cadascú. Aquesta línia de pensament queda molt remarcada en el D.C., "està molt de moda" parlar de la diversitat dins l'aula, però la nostra experimentació no ha tingut prou eines per a poder aprofundir en el planteig d'aquesta proposta i oferir alternatives concretes.

EI nou D.C. s'ha estructurat en tres Nivells de Concreció. El 1er. Nivell determina el Objectius Terminals, els grans blocs de Continguts i les Orientacions Didàctiques i d'Avaluació de cada àrea. El $2 n$. Nivell especifica els Continguts a treballar a cada nivell (6è, 7 ì i 8 è d'EGB). A partir d'aqui cada escola ha d'elaborar el 3er. Nivell, adaptat a les característiques sòcioculturals dels alumnes, a les possibilitats del centre...

La nostra feina com a mestres experimentadors ha sigut elaborar Tercers Nivells de Concreció, posar a la pràctica els que ens donaven, elaborats pels especialistes de cada àrea, i comprovar si era possible el desenvolupament d'aquest programa.

Una de les novetats que presenta aquest D.C. és la seva estructuració en tres tipus de Continguts:

- Els Fets, Conceptes i Sistemes Conceptuals

- Els Procediments

- Les Actituds, Valors i Normes.

És positiu que s'intenti superar el fet d'associar el terme Contingut als aspectes purament conceptuals, sense valorar degudament altres vessants de l'aprenentatge (destreses, habilitats, actituds...). La programació d'un 3er. Nivell de Concreció ha de contemplar els tres tipus de Continguts, donant-los importància similar per tal de fugir d'un ensenyament memorístic, centrat únicament en l'aspecte de Fets, Conceptes,... i obrint la porta a l'observació, l'experi- 


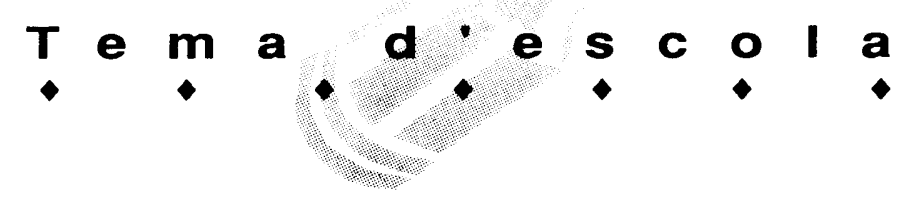

mentació, la manipulació... i a la potenciació d'actituds positives, pròpies de cada àrea.

A la pràctica, però, com hem de plantejar els 3rs. Nivells de CXoncreció per fer un aprenentatge significatiu?, Com hem de tractar la diversitat al cicle superior d'EGB amb un sol mestre per a tot el grup classe? Per desenvolupar aquests aspectes, el Pla de Reforma va procurar informar els mestres que hi participàvem de la seva importància, de la necessitat de tenir-ho present a l'hora de plantejar els temes, però no es van facilitar models concrets extrapolables a la pràctica quotidiana, sinó que es va deixar al criteri del mestre la seva aplicació. Tampoc no es va facilitar més personal per trobar noves estratègies d'organització i d'atenció als alumnes amb diferents capacitats d'aprenentatge.

Des del punt de vista dels Continguts ens hem trobat que algunes àrees (Llenguatge, Matemàtiques...) presenten força dificultats per diferenciar els Fets, Conceptes... dels Procediments, ja que per la naturalesa de la pròpia matèria els dos tipus de continguts estan molt interrelacionats i es fa molt difícil esbrinar si en una activitat concreta es treballa un concepte, un procediment o les dues coses a la vegada.

Si el D.C. concedeix una importància especial als Procediments, $i$ això és un punt de millora respecte als programes anteriors; s'ha de pensar que treballar procediments és una feina lenta i que requereix molt de temps. Si, per exemple, un dels procediments proposats és "elaborar una preparació cel.lular i ob-

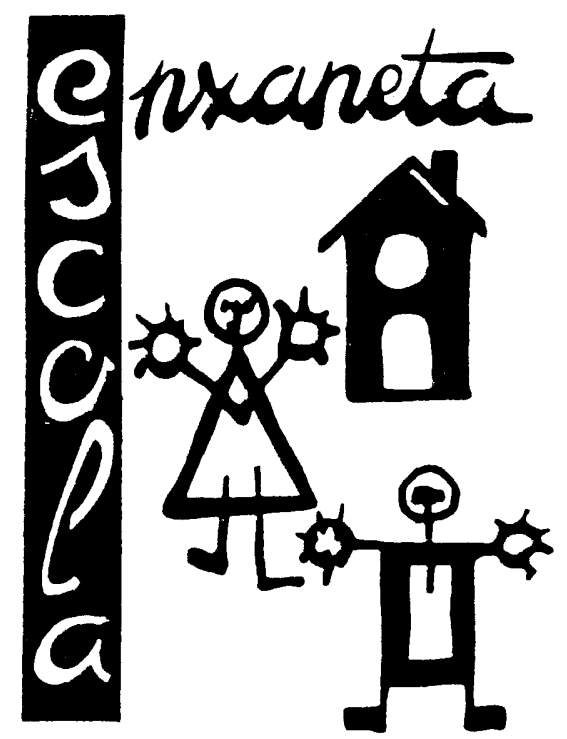

servar-la al microscopi", i això ho plantegem com una activitat a realitzar per tots els alumnes, voldrà dir que es necessitarà o molt de material (fet que no succeeix en la majoria d'escoles) per a dur-la a terme en poc temps o necessitarem moltes sessions de classe. Si hem de dedicar temps a treballar Procediments, no ens en queda tant per a treballar Conceptes.

Globalment pensem que el D.C. experimentat està excesivament carregat de continguts, i el que inicialment era una proposta de "mínims", al llarg de l'experimentació es va constatar que la totalitat dels Objectius Terminals de cada àrea no eren assolibles, ja que quedaven continguts sense treballar.

Les Actituds, Valors i Normes presenten una problemàtica diferent. Per una banda, se'ns demana als mestres que plantegem els temes amb una determinada visió i que es potenciïn unes certes actituds; per exemple, una actitud a treballar en Matemàtiques és que "l'alumne capti les formes geomètriques des d'un punt de vista dinàmic". Això implica que el mestre plantegi les activitats en aquesta linia. Per altra ban$\mathrm{da}$, al ser les A.V.N considerades com a continguts, vol dir que són avaluables i per tant els alumnes les han de treballar i posar de manifest, i el mestre ha de recollir aquesta manifestació per poder-la expressar en un full d'avaluació. A la pràctica es fa difícil treballar i avaluar les A.V.N d'una manera sistemàtica, ja que poques vegades el mestre pot esdevenir observador extern del procés de classe per tal de registrar les conductes i manifestacions dels alumnes que posin de manifest si han assolit o no tal actitud o tal altra.

En les consideracions generals del D.C. també es fa esment, d'una manera especial, a la interdisciplinarietat com una forma d'afavorir la significativitat dels aprenentatges. Però la paradoxa es troba en el fet que el propi D.C. està compartimentat en àrees i no presenta, d'entrada, una estructura que faciliti el tractament dels temes d'una manera interdisciplinària. Els pocs models que des de l'experimentació ens van oferir no responien a les expectatives proposades, $\mathrm{i}$ resultaven molt forçats de dur-los a la pràctica.

El nou currículum comporta un treball molt intens per part de l'equip de mestres, ja que introdueix la idea de cicle, de tractar la diversitat d'alumnes, el fet d'avaluar els tres nivells de continguts, la qual cosa implica marcar i seguir una línia de treball més en comú. Aquest treball en equip requereix una dinàmica de funcionament no sempre fàcil de realitzar (hores de reunió, presa de decisions...).

La figura del mestre-tutor adquireix un paper important, ja que és l'encarregat d'orientar l'alumne, 


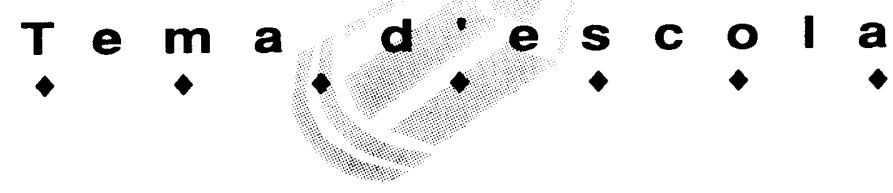

coordinar els diferents mestres que intervenen en el procés d'aprenentatge, establir els contactes amb els pares i, en definitiva, ser el globalitzador de les accions educatives que afecten l'alumne.

Un altre aspecte innovador és la manera com s'avalua. A l'estar diversificats els Continguts, també es diversifica l'Avaluació. S'avaluen per separat els tres aspectes dels Continguts i se n'extreu una nota global en cada àrea. Al mateix temps s'informa els pares de qüestions que fan referència a la Maduració Personal de cada alumne i a la Sociabilitat. Caldria trobar el temps i la manera de marcar unes pautes d'observació més sistemàtiques d'aquests dos últims aspectes; si no, es corre el perill de ser excessivament subjectius en l'apreciació dels ítems a valorar.

Per tal de mantenir la idea de cicle no es dóna una nota de final de curs de cada àrea, sinó que s'enregistren les notes per trimestres i al final de 8 è es qualifica amb una nota global de tot el cicle. Aquesta mecànica d'avaluació fa més necessari que es contempli com un procés continu que posi de manifest els diferents estadis d'aprenentatge en què es troba cada alumne. Aquest sistema d'avaluació i d'informació als pares implica una quantitat més gran de notes per matèria. Per una banda, l'alumne i la seva família veuen reflectida més realment la seva situació d'apre-

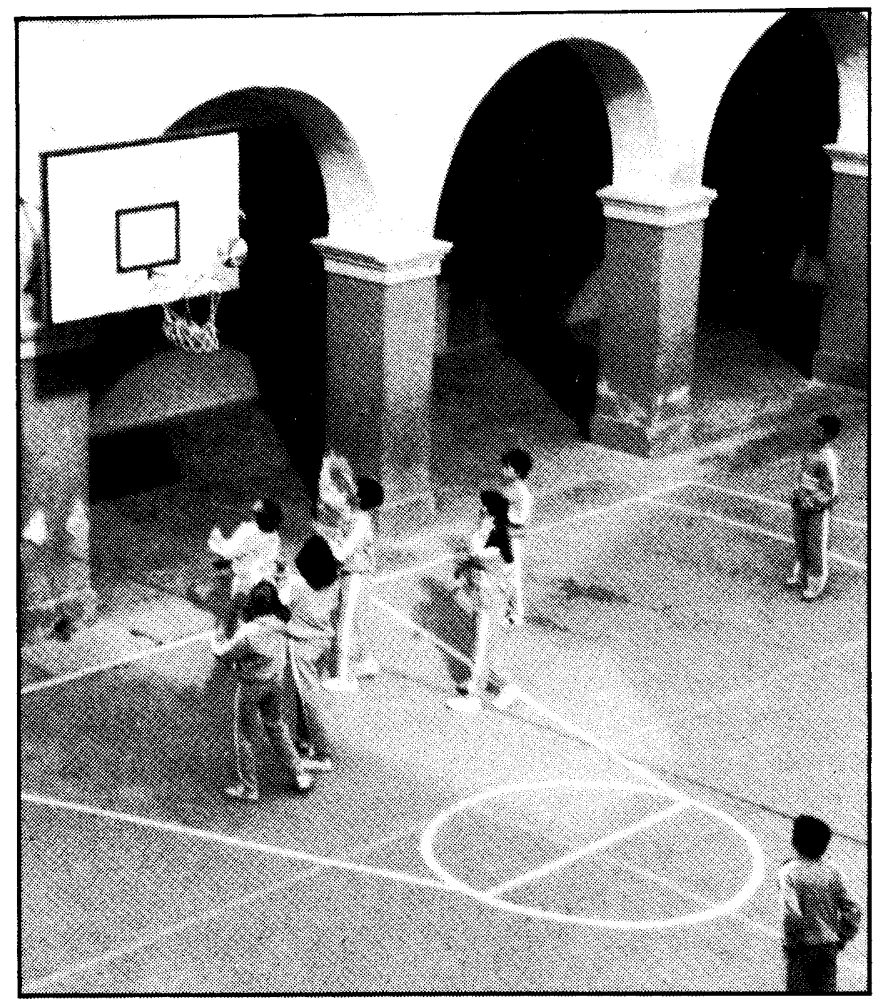

nentatge i permet que els que són constants en el treball quotidià vegin recompensats els esforços realitzats i els sigui un estimul per a tirar endavant; per altra banda, els alumnes que no treballen constaten amb escreix la seva realitat i l'allau d'insuficients acostuma a resultar molt desmotivador, i pot fer que es resignin a la situació i creguin que és inútil qualsevol esforç per millorar.

En un altre ordre de coses, cal constatar que la nostra escola per dur a terme l'experimentació va rebre recursos materials (llibres, dossiers...), diners per adquirir nou material $i$ altres recursos en forma d'assesoraments als mestres implicats de temes de caire general (tutoria, el D.C., l'avaluació...) i de caire més específic de cada àrea, a càrrec dels especialistes que havien dissenyat les programacions respectives. Tot $i$ això, tampoc podem considerar que fossin suficients, en part a causa de la poca concreció que presentava el D.C. que experimentàvem i a la molta feina que hi havia a fer. A mesura que es treballava s'anava ajustant aquest D.C., sobretot en la part que afectava directament els alumnes (3rs. Nivells de Concreció).

L'adaptació de la nostra escola a aquest nou D.C. no va suposar un trencament amb la línia general de treball que es portava a terme. Es van haver d'adaptar els continguts d'algunes àrees més que d'altres (C.Socials, C. Naturals, Tecnologia...), es va haver d'adoptar i assimilar la nova terminologia, i ens vam trobar amb d'altres dificultats com les que hem mencionat al llarg de l'article. Malgrat tot, considerem que, tot i l'esforç que va suposar per als mestres, l'experiència ha estat positiva, ha afavorit la reflexió, ha suposat un reciclatge, un contacte amb d'altres escoles..., i creiem també que una millora per als alumnes.

A partir de la nostra experiència creiem que l'administració educativa ha de pensar que la generalització de qualsevol Reforma ha de portar implicita una forta inversió econòmica, un pla seriós de formació del professorat, una motivació professional per als mestres que hi han de participar, i una informació als diversos sectors de la societat que hi estan implicats; si no és així, es corre el risc de reformar únicament la façana (canvi de terminologia...) i no emprendre una reforma en profunditat.

Pep Cunillera i Miquel Montserrat Robusté i Claravalls mestres de l'Escola Enxaneta, de Valls 